\title{
"Finding a Voice": Imaging Features after Phonosurgical Procedures for Vocal Fold Paralysis
}

\author{
(D) B.A. Vachha, DD.T. Ginat, (DP. Mallur, (D) M. Cunnane, and (D) G. Moonis
}

\begin{abstract}
SUMMARY: Altered communication (hoarseness, dysphonia, and breathy voice) that can result from vocal fold paralysis, secondary to numerous etiologies, may be amenable to surgical restoration. In this article, both traditional and cutting-edge phonosurgical procedures targeting the symptoms resulting from vocal fold paralysis are reviewed, with emphasis on the characteristic imaging appearances of various injectable materials, implants, and augmentation procedures used in the treatment of vocal fold paralysis. In addition, complications of injection laryngoplasty and medialization laryngoplasty are illustrated. Familiarity with the expected imaging changes following treatment of vocal fold paralysis may prevent the misinterpretation of posttreatment changes as pathology. Identifying common complications related to injection laryngoplasty and localization of displaced implants is crucial in determining specific management in patients who have undergone phonosurgical procedures for the management of vocal fold paralysis.
\end{abstract}

ABBREVIATIONS: PTFE = polytetrafluoroethylene; VFP $=$ vocal fold paralysis

V ocal fold paralysis (VFP) is the immobilization of the true vocal fold by neural injury (ipsilateral vagus or recurrent laryngeal nerve). ${ }^{1,2}$ Although many cases of VFP remain asymptomatic, altered communication (hoarseness, dysphonia, and breathy voice) and decreased airway protection resulting in aspiration are often seen due to glottic incompetency. Altered sensation, pharyngeal weakness, and swallowing incoordination, among other factors, may contribute to the propensity for aspiration. Conversely, bilateral VFP manifests primarily with dyspnea and biphasic stridor, with dysphonia and dysphagia occurring less frequently.

The main goal of intervention in a patient with unilateral VFP is to eliminate the risk of aspiration pneumonia and restore voice quality. ${ }^{3}$ Intervention involves both noninvasive voice therapy and surgical procedures. Voice therapy by a speech language pathologist is invaluable in the management of VFP both in the

From the Department of Radiology (B.A.V.), Memorial Sloan Kettering Cancer Center, New York, New York; Department of Radiology (B.A.V.), Massachusetts General Hospital, Harvard Medical School, Boston, Massachusetts; Department of Radiology (D.T.G.), University of Chicago, Chicago, Illinois; Department of Otology and Laryngology (P.M.), Beth Israel Deaconess Medical Center, Harvard Medical School, Boston, Massachusetts; Department of Radiology (M.C.), Massachusetts Eye and Ear Infirmary, Harvard Medical School, Boston, Massachusetts; and Department of Radiology (G.M.), Columbia University Medical Center, New York, New York.

Please address correspondence to Behroze Vachha, MD, PhD, Department of Radiology, Memorial Sloan Kettering Cancer Center, 1275 York Ave, New York, NY 10065; e-mail: vachhab@mskcc.org

- Indicates open access to non-subscribers at www.ajnr.org

http://dx.doi.org/10.3174/ajnr.A4781 preoperative setting when surgical decisions are being made and for optimal postsurgical phonation training; this however is beyond the scope of the present article. ${ }^{3}$ Surgical procedures for unilateral VFP aim to restore glottic competence by restoring vocal fold tone, augmenting vocal fold size, or altering static vocal fold position; to date, no surgical procedures in clinical use are able to restore purposeful vocal fold motion.

The term "phonosurgery" was originally introduced to describe surgical procedures targeting the voice. ${ }^{4}$ Surgical options differ on the basis of whether the patient has unilateral or bilateral VFP. Radiologic imaging has limited utility with respect to primary preoperative planning because glottic competence cannot be evaluated through existing radiologic modalities. While laryngoscopy with stroboscopy is the principal driver of treatment selection in vocal fold paralysis, preoperative imaging should be an adjunct when certain pathologic states are anticipated. For example, altered anatomy after neck surgery or radiation may change the surgical approach, suspicion of chondronecrosis may preclude framework surgery, and paralysis in the setting of laryngeal cartilage fracture may require attention to fracture fixation before phonosurgery, especially if mucosal violation is suggested by imaging.

Here we focus on the main types of procedures performed for the treatment of unilateral VFP, including injection laryngoplasty, medialization laryngoplasty, and arytenoid adduction. ${ }^{5,6}$ The indications, techniques, and corresponding imaging features are summarized in Table 1, schematized in Fig 1, and elaborated in the following sections. 
Table 1: Overview of vocal cord procedures

\begin{tabular}{|c|c|c|c|}
\hline Procedures & Indications & Techniques & Imaging Findings \\
\hline Injection laryngoplasty & $\begin{array}{l}\text { Temporary correction of glottic incompetence } \\
\text { due to unilateral vocal fold paralysis and } \\
\text { long-term correction of mild-moderate } \\
\text { glottic insufficiency }\end{array}$ & $\begin{array}{l}\text { Percutaneous, transnasal, or } \\
\text { peroral injection of filler } \\
\text { material into the vocal cord } \\
\text { or paraglottic space }\end{array}$ & $\begin{array}{l}\text { Varies depending on agent } \\
\text { injected; also refer to } \\
\text { the text and Table } 2\end{array}$ \\
\hline $\begin{array}{l}\text { Medialization } \\
\text { laryngoplasty }\end{array}$ & $\begin{array}{l}\text { Permanent correction; should be reserved for } \\
\text { cases of vocal fold paralysis in which } \\
\text { recovery of motion is definitively not } \\
\text { expected (time }>6 \text { months from onset, } \\
\text { surgical recurrent nerve sacrifice, or } \\
\text { malignant invasion) }\end{array}$ & $\begin{array}{l}\text { Insertion of an implant into the } \\
\text { vocal fold through a window } \\
\text { in the thyroid, which results } \\
\text { in displacement of the } \\
\text { paralyzed vocal fold to a } \\
\text { more medial position }\end{array}$ & $\begin{array}{l}\text { The implants typically } \\
\text { used appear as } \\
\text { hyperattenuating on CT } \\
\text { and low signal on } \\
\text { T1- and T2-weighted } \\
\text { sequences, with a } \\
\text { triangular shape on axial } \\
\text { images; a defect in the } \\
\text { adjacent thyroid } \\
\text { cartilage may be visible }\end{array}$ \\
\hline $\begin{array}{l}\text { Arytenoid adduction } \\
\quad \text { (adduction } \\
\text { arytenopexy) }\end{array}$ & $\begin{array}{l}\text { To enhance posterior glottal closure in } \\
\text { patients with paralytic dysphonia by } \\
\text { reproducing lateral cricoarytenoid muscle } \\
\text { function; can be performed in conjunction } \\
\text { with medialization laryngoplasty }\end{array}$ & $\begin{array}{l}\text { The inner perichondrium of the } \\
\text { thyroid cartilage is opened } \\
\text { and the muscular process of } \\
\text { the arytenoid is identified and } \\
\text { sutured to the thyroid or } \\
\text { cricoid cartilage }\end{array}$ & $\begin{array}{l}\text { Medially rotated } \\
\text { (adducted) arytenoid } \\
\text { cartilage and narrowing } \\
\text { of the posterior glottic } \\
\text { gap }\end{array}$ \\
\hline
\end{tabular}
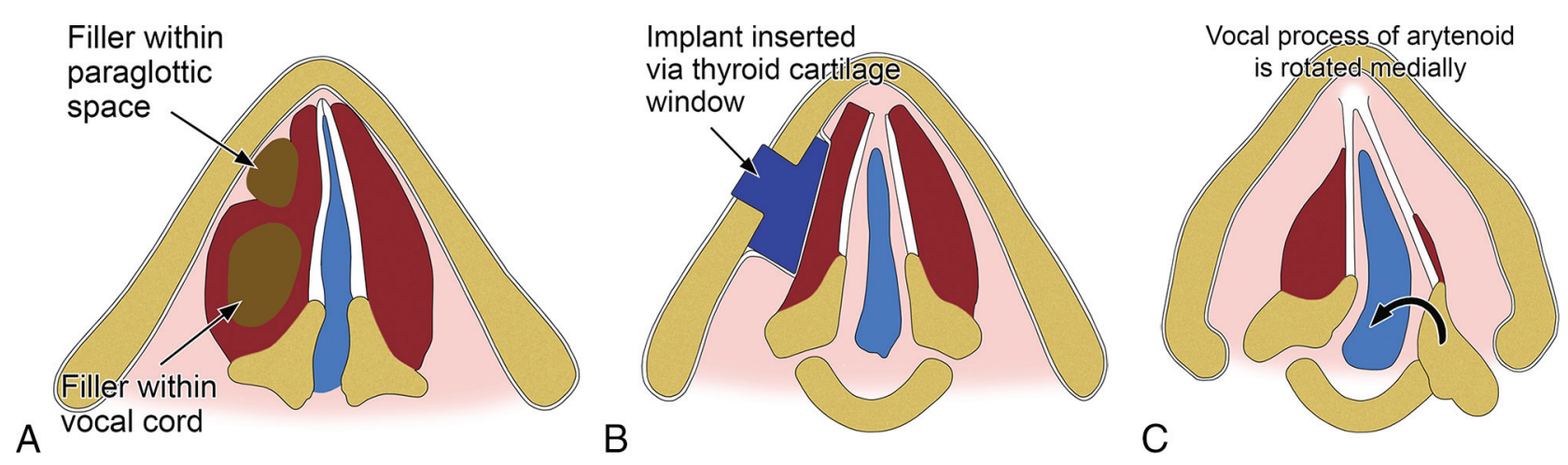

FIG 1. Schematic of the main categories of procedures for treating vocal cord paralysis: injection laryngoplasty $(A)$, medialization laryngoplasty $(B)$, and arytenoid adduction (C).

Table 2: Description of selected agents used for injection laryngoplasty

\begin{tabular}{|c|c|c|}
\hline Agents & Longevity & Imaging Findings \\
\hline Hyaluronic acid gels (Restylane, Hylaform) & Temporary & $\begin{array}{l}\text { Nearly fluid attenuation on } \mathrm{CT} ; \mathrm{T} 1 \text { hypointense and } \mathrm{T} 2 \text { hyperintense, similar to } \\
\text { fluid on MRI; may display peripheral enhancement initially }\end{array}$ \\
\hline Micronized cadaveric dermis (Cymetra) & Temporary & $\mathrm{T} 1$ and $\mathrm{T} 2$ hyperintense within the first year of injection \\
\hline Bovine collagen preparations (Zyplast) & Temporary & $\begin{array}{l}\text { Generally fluid attenuation on } \mathrm{CT} ; \mathrm{T} 1 \text { hypointense and } \mathrm{T} 2 \text { hyperintense, similar } \\
\text { to fluid on MRI; may display peripheral enhancement initially }\end{array}$ \\
\hline Calcium hydroxylapatite (Radiesse Voice) & Long-lasting & High attenuation on CT (280-700 HU); hypermetabolic on ${ }^{18} \mathrm{FDG}-\mathrm{PET}$ \\
\hline Autologous fat & Long-lasting & Attenuation and signal characteristics of adipose tissue \\
\hline Teflon & Permanent & Globular high attenuation on CT (200-400 HU range) \\
\hline
\end{tabular}

\section{Injection Laryngoplasty}

Injection laryngoplasty or vocal fold augmentation involves injection of various materials into the lateral aspect of the thyroarytenoid/lateral cricoarytenoid muscle complex of the paralyzed vocal fold. ${ }^{7}$ Alternatively, materials can be injected lateral to the thyroarytenoid in the paraglottic space. The result of either is a medially displaced free edge of the affected vocal fold, improving its apposition with the contralateral vocal fold.

The main indications for vocal fold injection include temporary correction of glottic incompetence due to unilateral VFP and long-term correction of mild-moderate glottic insufficiency (ie, glottic gap of $<1-3 \mathrm{~mm}) .^{7-9}$

Injection laryngoplasty is a minimally invasive procedure that can be performed with the patient under general anesthesia by using microscopic suspension laryngoscopy or it can be performed as an in-office procedure with the patient under local anesthesia. ${ }^{8-12}$ Three endoscopic approaches may be used in the office with a flexible laryngoscope: percutaneous (transcricothyroid membrane, transthyroid cartilage, and transthyrohyoid membrane), transnasal, and peroral. ${ }^{7}$

\section{Injection Materials}

The first attempt of vocal fold augmentation involved the use of paraffin injected through a 19-ga needle. ${ }^{10}$ Since then, different materials have been used for vocal fold augmentation. Currently, materials used for vocal fold injection/augmentation are divided 

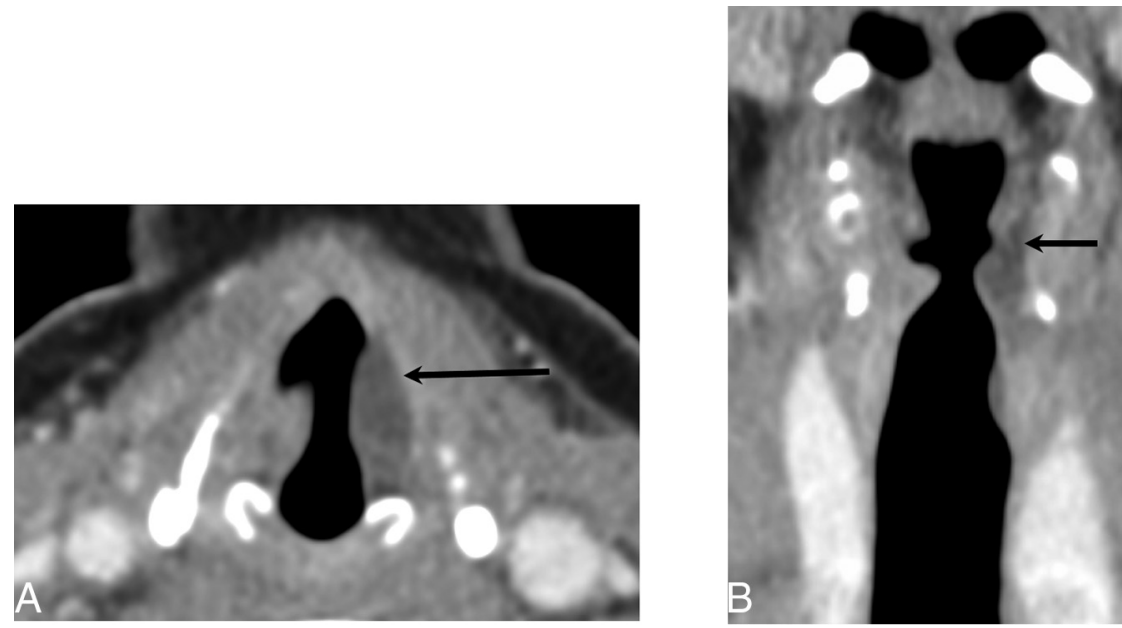

FIG 2. Hyaluronic acid gel. Axial $(A)$ and coronal $(B)$ contrast-enhanced $C T$ at the level of the vocal folds demonstrates fluid attenuation material within the left vocal fold (black arrow).
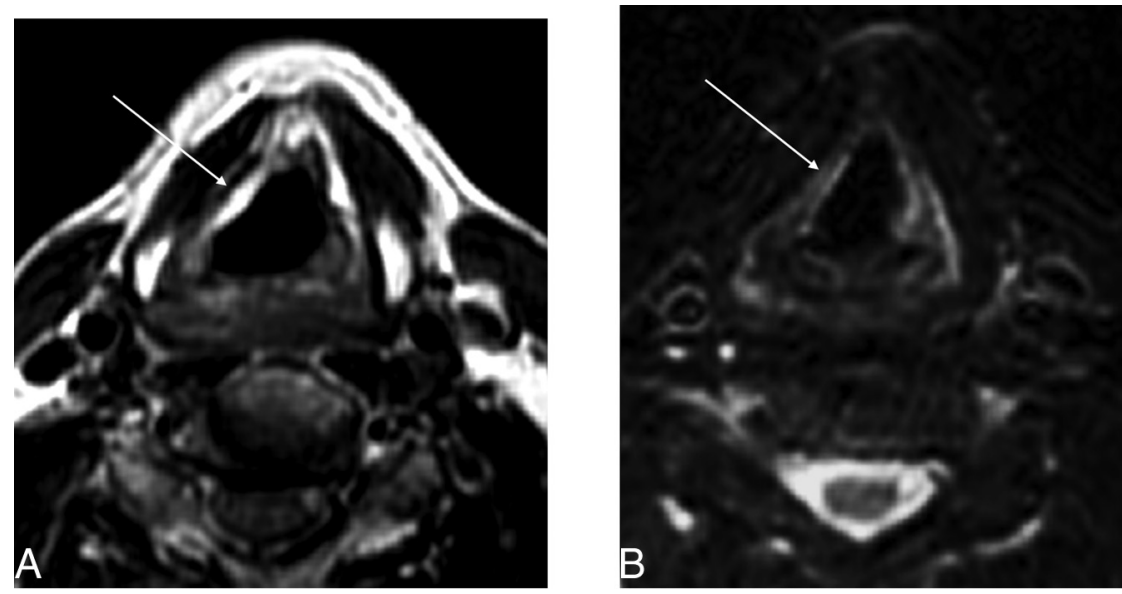

FIG 3. Micronized collagen (Cymetra) approximately 11 months after injection. $A$, Unenhanced T1-weighted image at the level of the true vocal folds demonstrates $T 1$ hyperintensity within the right vocal fold (arrow; due to volume averaging, portions of the false cord are also partially seen). $B$, T2-weighted image demonstrates a hyperintense region in the true vocal fold on the right corresponding to the site of injection (arrow).
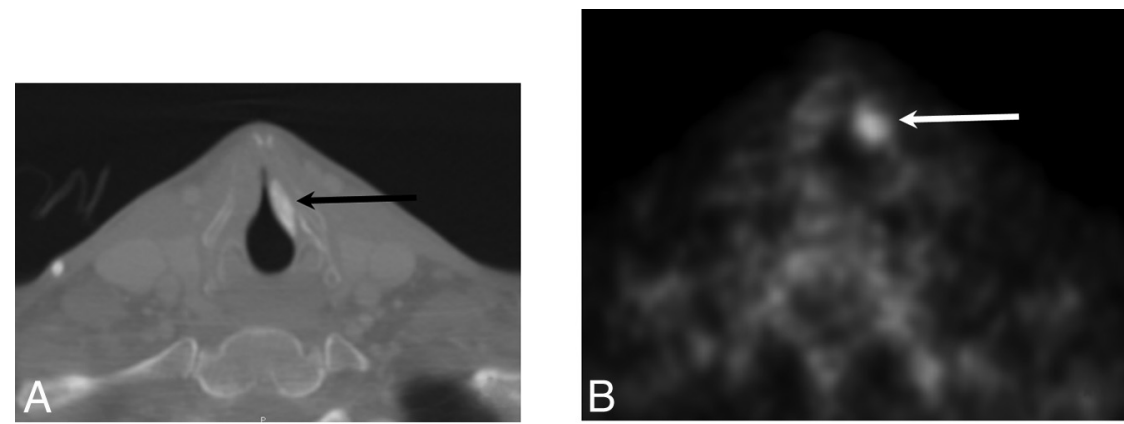

FIG 4. Calcium hydroxylapatite. A, Axial contrast-enhanced CT with a bone algorithm demonstrates hyperattenuating material in the region of the left vocal fold (black arrow). B, Axial positron-emission tomography demonstrates hypermetabolism at the site of the injected material, which can be a false-positive finding for malignant disease (white arrow).

into temporary and long-lasting. Temporary materials include carboxymethylcellulose (Radiesse Voice Gel; BioForm Medical, Franksville, Wisconsin), hyaluronic acid gel (Restylane; Q-Med Scandinavia, Princeton, Virginia; Hylaform; Q-Med, Uppsala,
Sweden), micronized collagen (Cymetra; LifeCell Corporation, Bridgewater, New Jersey), bovine collagen (Zyplast; Advanced Dermatology PC, New York, New York), and bovine gelatin (Gelfoam; Pfizer, New York, New York; Surgifoam; Ethicon, Centreville, Virginia). ${ }^{7}$ Longlasting materials include calcium hydroxylapatite (Radiesse Voice; BioForm Medical), autologous fat, and, of historic importance, polytef paste (Teflon; Dupont, Wilmington, Delaware). ${ }^{7}$ The imaging features following injection laryngoplasty vary depending on the particular agent used, as described in the subsequent sections and Table 2 .

Temporary Materials. Hyaluronic acid gels (eg, Restylane and Hylaform) are composed of water in a glycosaminoglycan matrix with a reported duration of clinical effects lasting from 4 to 6 months, though it may be detectable even 12 months after injection. ${ }^{11-13}$ On CT, hyaluronic acid demonstrates nearly fluid attenuation (Fig 2). On MR imaging, the material is T1 hypointense and T2 hyperintense with an imaging appearance similar to that of water. On postcontrast T1weighted sequences, this material may show minimal peripheral enhancement. ${ }^{14}$ Clinical studies have supported the safety and efficacy of hyaluronic acid gels in deep vocal fold augmentation in patients with VFP.

Micronized cadaveric dermis (Cymetra) is donor skin (Alloderm; LifeCell Corporation) that has been processed into a nonimmunogenic acellular matrix of human collagen and elastin. ${ }^{15}$ This material has demonstrated positive results in the treatment of VFP, with several advantages over other injection materials: Because the material is acellular, it does not incite a foreign body or hypersensitivity reaction (compare it with bovine collagen materials); no harvesting of tissue is required, thereby reducing operative time and alleviating donor site morbidity (compare with autologous fat); and injection of this material does not inhibit vibratory function (compare with hyaluronic acid gels). ${ }^{15-17}$ The main disadvantage of this material is the need for overinjection to overcome unwanted absorption of the material. ${ }^{15}$ Because the material is prepared from human cadaveric dermis, there is the theoretic risk of infectious transmission, though this has not been reported clinically, to our knowledge. 

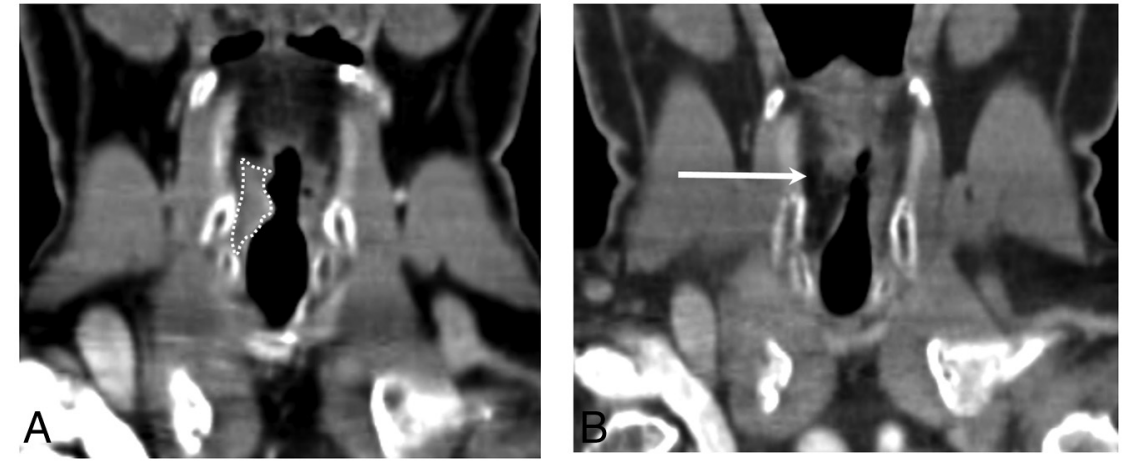

FIG 5. Autologous fat. $A$, Coronal $C T$ at the level of the vocal folds demonstrates transglottic carcinoma on the right (white dotted line). $B$, Coronal CT posttreatment shows low-attenuation material within the right vocal fold status post fat augmentation (arrow).
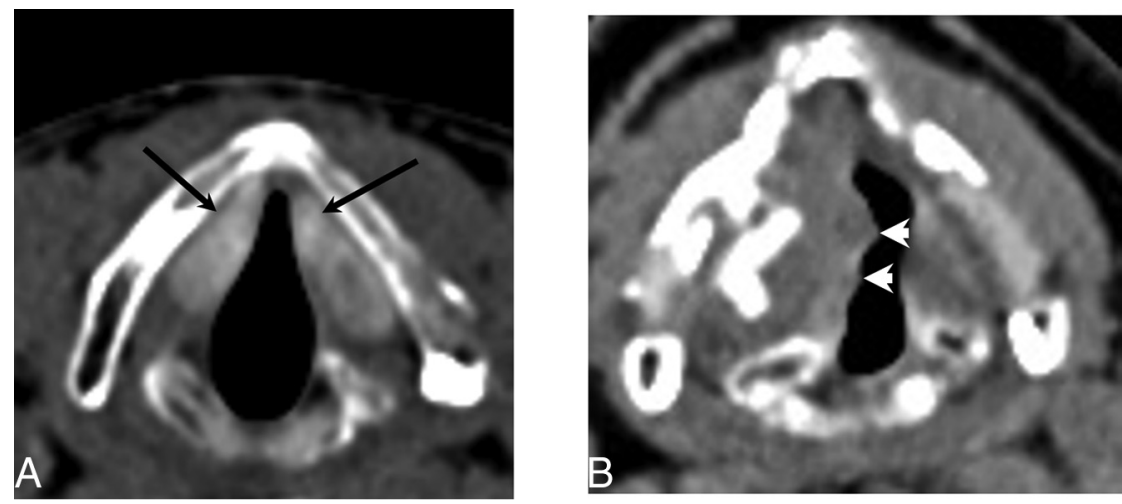

FIG 6. Teflon. A, Axial CT demonstrates hyperattenuating material in the bilateral vocal folds (arrows) consistent with Teflon injection. B, Axial CT in a different patient status post Teflon injection into the right vocal fold demonstrates a slightly nodular contour (arrowheads) consistent with granuloma formation, a common complication of Teflon.

The time course of Cymetra resorption follows a pattern that could be observed by MR imaging: Until about 11 months, the material appears T1 and T2 hyperintense (Fig 3); by 15 months, there is minimal $\mathrm{T} 2$ hyperintensity; and by 21 months postinjection, there is no signal alteration within the vocal folds, suggesting complete resorption of the injected material into the recipient tissue. $^{16}$

Bovine collagen materials such as Zyplast may result in hypersensitivity reactions prompting skin hypersensitivity testing before using this material. ${ }^{7,9}$ Bovine gelatin material has been shown to be safe with predictable results as a temporary augmentation material, but the need for large-gauge needles (18- or 19-ga) and the short duration of effect ( $4-6$ weeks) have resulted in it being less popular than its newer, longer-lasting counterparts., ${ }^{7,9}$

Long-Lasting and Permanent Materials. Calcium hydroxylapatite (Radiesse Voice) consists of microspheres of calcium hydroxylapatite in a carboxymethylcellulose carrier and has been shown to provide clinical effectiveness for an average duration of approximately 18 months postinjection. ${ }^{18,19}$ Calcium hydroxylapatite appears as high-attenuation material on CT, with attenuation values ranging between 280 and $700 \mathrm{HU}$ (Fig 4A). ${ }^{14}$ Calcium hydroxylapatite can appear hypermetabolic on ${ }^{18} \mathrm{~F}$-FDG-positronemission tomography and should not be misinterpreted as a neoplasm (Fig 4B).

Autologous fat is usually harvested from the patient by a lipo- suction technique. At least initially, this filler preserves the expected imaging features of adipose tissue (Fig 5). Variability in resorption limits the predictability of the long-term voice outcomes; furthermore, the patient may require substantial overinjection and repeat lipoinjection to achieve adequate results. ${ }^{7}$

Teflon appears as hyperattenuating on CT (Fig 6). The use of this material is now avoided due to serious complications related to granuloma formation, which can appear as a soft-tissue mass surrounding the hyperattenuating Teflon. ${ }^{7}$ Furthermore, the Teflon-induced granulomas can potentially produce false-positive findings on ${ }^{18}$ F-FDG-positron-emission tomography, but the true nature of this phenomenon can be resolved by the otherwise suggestive CT appearance. $^{20}$

\section{Laryngeal Framework Surgery}

Although long-acting injection materials have become increasingly popular, laryngeal framework surgery remains the criterion standard long-term treatment of unilateral VFP. "Laryngeal framework surgery" is a nonspecific label referring to open surgical approaches to the cartilaginous framework. Surgical goals vary by type, and as expected, not all framework surgery is appropriate for unilateral VFP.

Broadly speaking, the 4 main categories are the following: 1) approximation laryngoplasty, which includes medialization thyroplasty/laryngoplasty and arytenoid adduction; 2) expansion laryngoplasty, which includes lateralization thyroplasty and vocal fold abduction; 3 ) relaxation laryngoplasty, which includes shortening thyroplasty; and 4) tensioning laryngoplasty, which includes cricothyroid approximation and elongation thyroplasty. ${ }^{21}$ Neither expansion nor relaxation laryngoplasty are appropriate for unilateral VFP because they are intended to improve glottic competence. Tensioning laryngoplasty may be used to restore tension often absent in unilateral VFP; however, it is usually not used, and the nuances of this procedure are beyond the scope of this article. For this review, we discuss medialization laryngoplasty and arytenoid adduction, which are the most commonly performed framework operations for unilateral VFP.

\section{Medialization Laryngoplasty}

Medialization laryngoplasty involves introducing an implant through an externally created window in the thyroid lamina at the level of the vocal fold, which results in displacement of the paralyzed vocal fold from its lateral position to a more medial position. ${ }^{5,22-25}$ Medialization laryngoplasty is a permanent correction and should be reserved for cases of vocal fold paralysis in which recovery of motion is definitively not expected (time $>6$ months from onset, surgical recurrent nerve sacrifice, or malignant inva- 

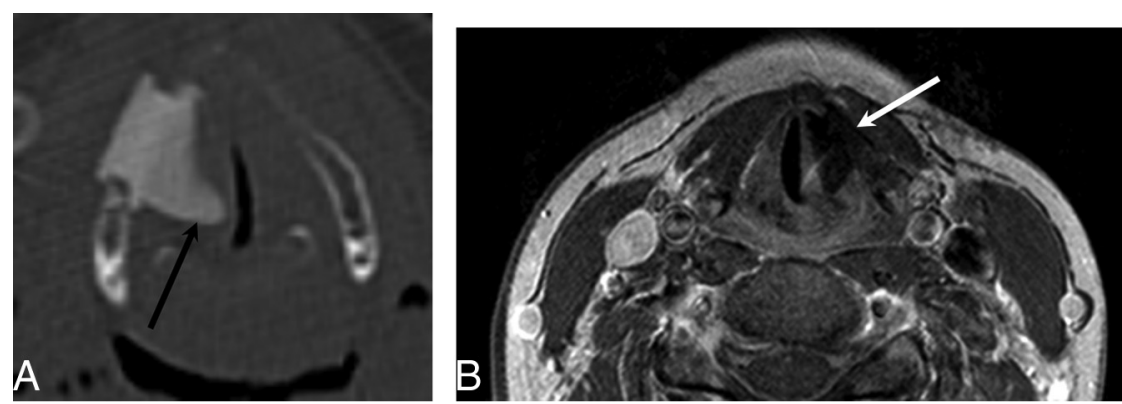

FIG 7. Montgomery Implant. A, Axial CT demonstrates a Montgomery Implant (black arrow) and appropriate medialization of the right vocal cord. Note the triangular configuration of the Montgomery Implant. B, Axial contrast-enhanced T7-weighted MR imaging in a different patient demonstrates triangular hypointensity adjacent to the left vocal fold, representing the Montgomery Implant (white arrow), with appropriate medialization of left vocal fold.

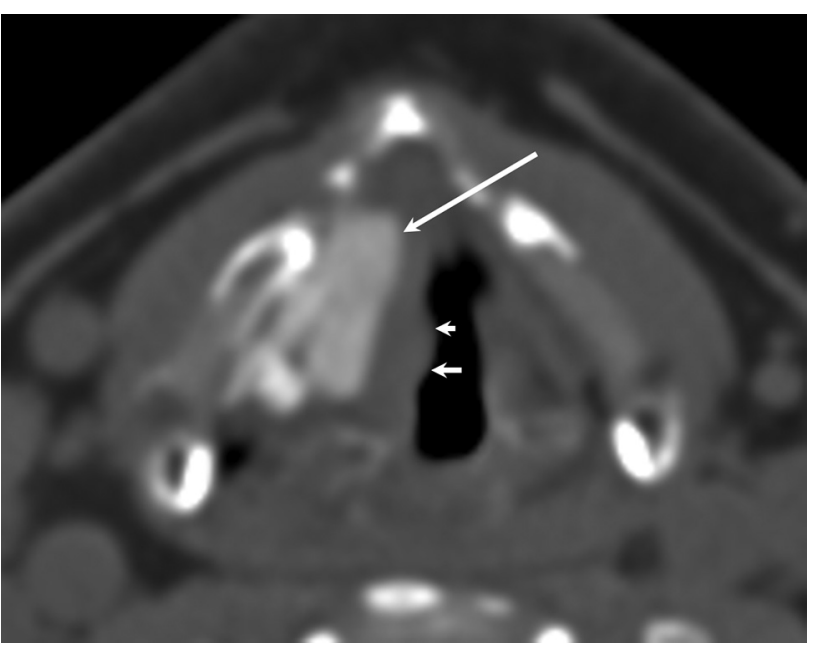

FIG 8. PTFE. Axial CT demonstrates hyperattenuating PTFE in the region of the right vocal fold with appropriate medialization of the right vocal fold. Note the slight nodular contour of the medial margin of the vocal fold (smaller arrows) indicating mild granuloma formation in this patient.

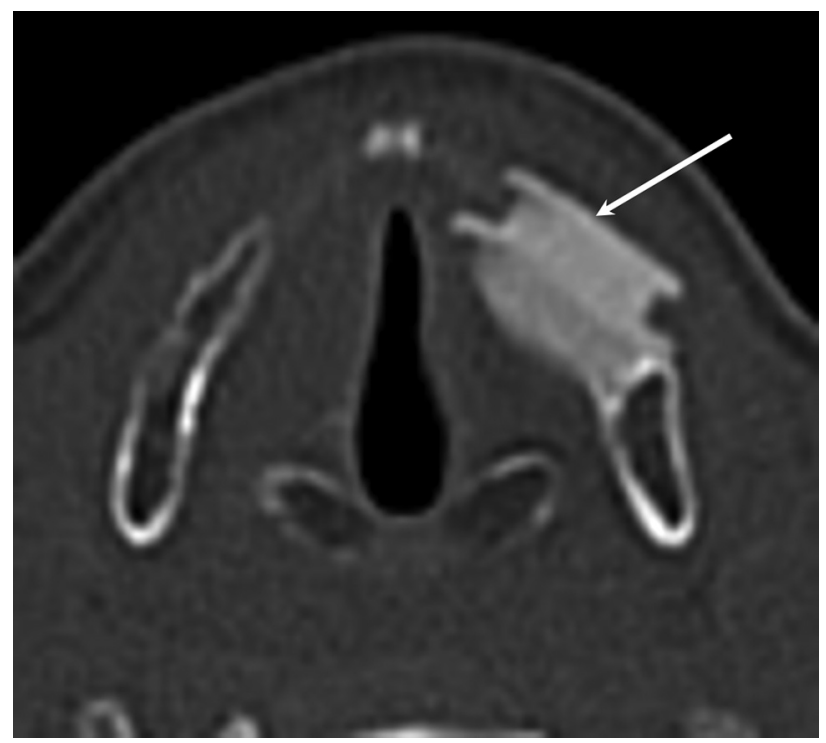

FIG 9. Malpositioned Montgomery Implant. Axial CT demonstrates an externally rotated Montgomery Implant, which is not flush against the thyroid window (arrow). sion). Medialization laryngoplasty offers several advantages, such as preservation of the mucosal wave, no risk of reabsorption of the implant, and implants generally being more easily removed than injected material. However, disadvantages of medialization laryngoplasty include the risk of submucosal hemorrhage and implant extrusion and the effects of suboptimal shaping of the implant. Several materials are used for medialization, including silicone, polytetrafluoroethylene (PTFE; Gore-Tex; W.L. Gore \& Associates, Newark, Delaware), hydroxylapatite (VoCom system; Gyrus ENT, Bartlett, Tennessee), Silastic (preformed or carved; Dow Corning, Midland, Michigan), and titanium implants. ${ }^{5}$

The Montgomery Thyroplasty Implant System (Boston Medical Products, Westborough, Massachusetts) is constructed of implant-grade silicone and is inserted surgically through the thyroid lamina at the level of the vocal fold to medialize the paralyzed vocal fold. ${ }^{26-28}$ On CT, Montgomery Implants are hyperattenuated and have a characteristic triangular configuration (Fig 7).

Polytetrafluoroethylene is an expanded form of Teflon. Unlike other implants, this is inserted through a window in the thyroid lamina in the form of 0.4 -mm-thick strips and layered in an accordion-like fashion in the paraglottic space. On CT, PTFE appears hyperattenuating with lobulated medial margins (Fig 8); this appearance helps distinguish it from a Montgomery Implant, which is triangular. ${ }^{26}$ Although the instances of inflammatory response due to PTFE are less common than those seen with Teflon, they can nevertheless occur. Other materials used for medialization include ceramic wedges made of hydroxylapatite and titanium implants.

Complications related to implant malpositions or displacement (Figs 9 and 10), extrusion, and excess implant material are occasionally seen and may require operative correction.

\section{Arytenoid Adduction}

In certain cases of VFP, the anatomic position of the paralyzed vocal fold precludes restoration of glottic competence with medialization alone and requires vocal fold repositioning through arytenoid adduction. This situation can occur with a lateralized vocal fold with a glottic gap of $\geq 4 \mathrm{~mm}$, which is typically too large to be overcome by simple medialization. Additionally, a paralyzed vocal fold will often be lower in vertical height because muscle flaccidity allows the arytenoid to slide anteriorly and twist in the caudal direction, dropping the vocal process; the resultant height mismatch prevents contact of the membranous vocal folds, contributing to glottic incompetence. Arytenoid adduction is an open approach to repositioning of the arytenoid cartilage. By placing a suture through the muscular process of the arytenoid and fixing this with anterior tension (typically through the cricothyroid membrane and above the anterior vocal fold commissure), the resultant vocal fold is medial and cranially displaced with increased longitudinal tension (Fig 11). ${ }^{5}$ This procedure addresses the posterior glottic gap by rotating the arytenoid vocal process, 

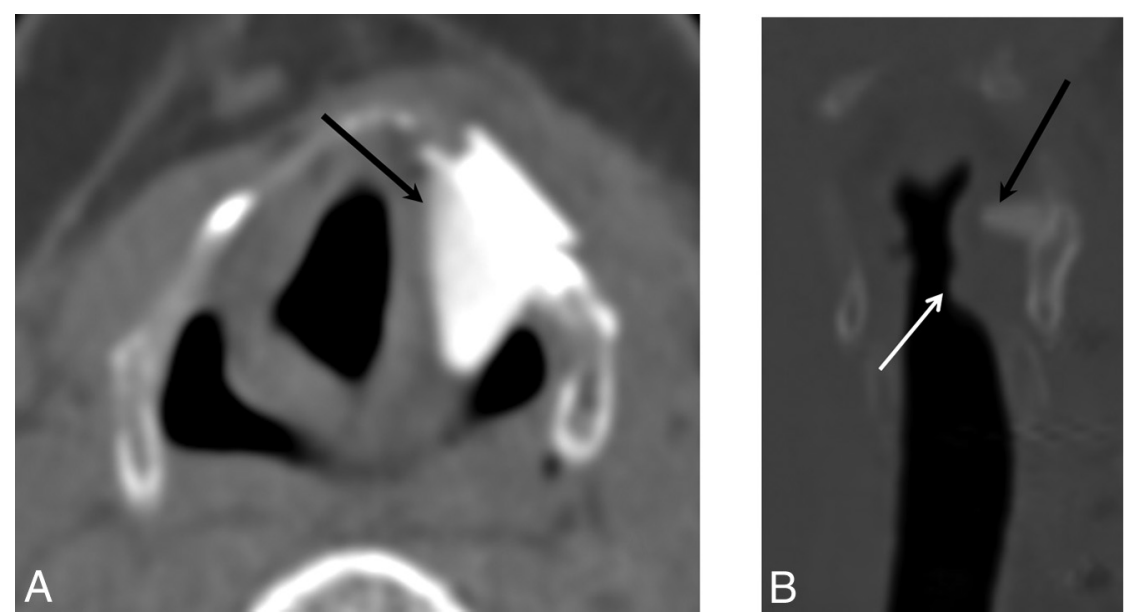

FIG 10. Malpositioned Montgomery Implant. Axial $(A)$ and coronal $(B)$ images demonstrate a Montgomery Implant that is displaced superiorly into the aryepiglottic fold and false cord (black arrow). White arrow indicates the appropriate level of the implant.
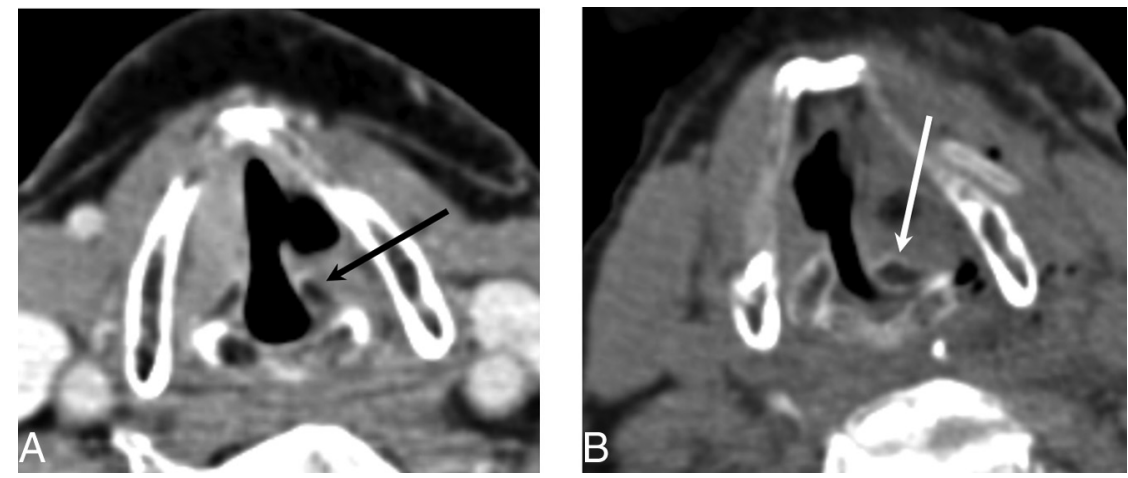

FIG 11. Arytenoid adduction. Preoperative axial CT image $(A)$ and postoperative axial CT image (B) demonstrate the medially rotated (adducted) left arytenoid cartilage (white arrow) compared with the preoperative position (black arrow). Note that adduction turns the arytenoid in toward the vocal cord to ensure that no air leaks through the posterior glottic gap. This result helps patients achieve a more robust voice quality after the operation.

positioning the vocal fold into an adducted position. This procedure is indicated when the interarytenoid gap is $>5 \mathrm{~mm}$, when there is height mismatch of the paralyzed and contralateral vocal fold, or when there is loss of vocal fold tension. This is usually performed in conjunction with medialization thyroplasty. ${ }^{5}$

\section{CONCLUSIONS}

Familiarity with the expected imaging changes following treatment of VFP may prevent the misinterpretation of posttreatment changes as pathology. Identifying common complications related to injection laryngoplasty and localization of displaced implants is crucial in determining specific management in patients who have undergone phonosurgical procedures for the management of VFP.

Disclosures: Gul Moonis—UNRELATED: Other: blind reader for RadMD.

\section{REFERENCES}

1. Benninger MS, Gillen JB, Altman JS. Changing etiology of vocal fold immobility. Laryngoscope 1998;108:1346-50 CrossRef Medline

2. Curtin H. The larynx. In: Som PM, Curtin HD, eds. Head and Neck Imaging. 4th ed. St. Louis: Mosby; 2003:1146-67

3. Rubin AD, Sataloff RT. Vocal fold paresis and paralysis. Otolaryngol Clin North Am 2007;40:1109-31, viii-ix Medline

4. Leden H. The history of phonosurgery. In: Gould WJ, Sataloff RT,
Spiegel JR, eds. Voice Surgery. Chicago: Mosby Year Book; 1993:65-96

5. Nawka T, Hosemann W. Surgical procedures for voice restoration. GMS Curr Top Otorhinolaryngol Head Neck Surg 2005;4:Doc14 Medline

6. Zeitels SM, Healy GB. Laryngology and phonosurgery. N Engl J Med 2003;349: 882-92 CrossRef Medline

7. Mallur PS, Rosen CA. Vocal fold injection: review of indications, techniques, and materials for augmentation. Clin Exp Otorhinolaryngol 2010;3:177-82 CrossRef Medline

8. Rosen CA, Statham MM. Vocal fold injection as a treatment for glottic insufficiency: pro. Arch Otolaryngol Head Neck Surg 2010; 136:825-27 CrossRef Medline

9. Sulica L, Rosen CA, Postma GN, et al. Current practice in injection augmentation of the vocal folds: indications, treatment principles, techniques, and complications. Laryngoscope 2010;120:319-25 CrossRef Medline

10. Bruening W. Uber eine neue behandlungsmethode der rekurrenslahmung. Verh Dtsch Laryng 1911;18:23

11. Hertegård S, Hallén L, Laurent C, et al. Cross-linked hyaluronan versus collagen for injection treatment of glottal insufficiency: 2-year follow-up. Acta Otolaryngol 2004;124:1208-14 CrossRef Medline

12. Hertegård S, Hallén L, Laurent $C$, et al. Cross-linked hyaluronan used as augmentation substance for treatment of glottal insufficiency: safety aspects and vocal fold function. Laryngoscope 2002; 112:2211-19 CrossRef Medline

13. Molteni G, Bergamini G, Ricci-Maccarini A, et al. Auto-crosslinked hyaluronan gel injections in phonosurgery. Otolaryngol Head Neck Surg 2010;142:547-53 CrossRef Medline

14. Ginat DT, Schatz CJ. Imaging features of midface injectable fillers and associated complications. AJNR Am J Neuroradiol 2013;34: 1488-95 CrossRef Medline

15. Tan M, Woo P. Injection laryngoplasty with micronized dermis: a 10-year experience with 381 injections in 344 patients. Laryngoscope 2010;120:2460-66 CrossRef Medline

16. Moonis G, Dyce O, Loevner LA, et al. Magnetic resonance imaging of micronized dermal graft in the larynx. Ann Otol Rhinol Laryngol 2005;114:593-98 CrossRef Medline

17. Lundy DS, Casiano RR, McClinton ME, et al. Early results of transcutaneous injection laryngoplasty with micronized acellular dermis versus type-I thyroplasty for glottic incompetence dysphonia due to unilateral vocal fold paralysis. J Voice 2003;17:589-95 CrossRef Medline

18. Rosen CA, Gartner-Schmidt J, Casiano R, et al. Vocal fold augmentation with calcium hydroxylapatite: twelve-month report. Laryngoscope 2009;119:1033-41 CrossRef Medline

19. Carroll TL, Rosen CA. Long-term results of calcium hydroxylapatite for vocal fold augmentation. Laryngoscope 2011;121:313-19 CrossRef Medline

20. Yeretsian RA, Blodgett TM, Branstetter BF, et al. Teflon-induced 
granuloma: a false-positive finding with PET resolved with combined PET and CT. AJNR Am J Neuroradiol 2003;24:1164-66 Medline

21. Friedrich G, de Jong FI, Mahieu HF, et al. Laryngeal framework surgery: a proposal for classification and nomenclature by the Phonosurgery Committee of the European Laryngological Society. Eur Arch Otorhinolaryngol 2001;258:389-96 CrossRef Medline

22. Selber J, Sataloff R, Spiegel J, et al. Gore-Tex medialization thyroplasty: objective and subjective evaluation. J Voice 2003;17: 88-95 CrossRef Medline

23. Shen T, Damrose EJ, Morzaria S. A meta-analysis of voice outcome comparing calcium hydroxylapatite injection laryngoplasty to silicone thyroplasty. Otolaryngol Head Neck Surg 2013;148:197-208 CrossRef Medline
24. Ford CN. Advances and refinements in phonosurgery. Laryngoscope 1999;109:1891-900 CrossRef Medline

25. Isshiki N, Morita H, Okamura H, et al. Thyroplasty as a new phonosurgical technique. Acta Otolaryngol 1974;78:451-57 CrossRef Medline

26. Laccourreye O, El Sharkawy L, Holsinger FC, et al. Thyroplasty type I with Montgomery implant among native French language speakers with unilateral laryngeal nerve paralysis. Laryngoscope 2005;115: 1411-17 CrossRef Medline

27. McLean-Muse A, Montgomery WW, Hillman RE, et al. Montgomery thyroplasty implant for vocal fold immobility: phonatory outcomes. Ann Otol Rhinol Laryngol 2000;109:393-400 CrossRef Medline

28. Montgomery WW, Montgomery SK. Montgomery thyroplasty implant system. Ann Otol Rhinol Laryngol Suppl 1997;170:1-16 Medline 